\title{
Methods of deconditioning persisting avoidance: Response prevention and counterconditioning after extensive training*
}

\author{
EUGENE VOSS, CHERYL MEJTA, and LARRY REID \\ Bradley University, Peoria, Ilinois 61606
}

\begin{abstract}
Rats were fixed with a chronically indwelling electrode for intracranial stimulation (ICS) of a site of stimulation that elicited positive affect. After recovery from surgery, each rat was forced to avoid or escape footshock for 100 trials/day for 10 days in an automated one-way avoidance chamber. After 1,000 trials, footshock was discontinued and trials measured to extinction. Between shock discontinuance and extinction trials, one group received time on the grid with the ledge removed, a response prevention treatment. Another group spent the same time in response prevention and also received periodic ICS, a counterconditioning treatment. A third group spent time outside the chamber, a no-treatment control. The group of counterconditioning responded reliably less during extinction. These data confirm the conclusion drawn from similar studies using only limited avoidance training that counterconditioning is a superior treatment for reducing persisting avoidance.
\end{abstract}

Avoidance responding, normally highly resistant to extinction, can be reduced by forcing the organism to remain in the situation which previously elicited active avoidance (response prevention) (Baum, 1970). Changing the affective state of the animal through the introduction of a positive affective stimulus during response prevention (counterconditioning) attenuates persistent avoidance even more (Wilson \& Davison, 1971; Reid, 1973). Positive intracranial stimulation (ICS) of the lateral hypothalamus has been used in some of the studies demonstrating the effectiveness of counterconditioning (Buss \& Reid, 1973; Gordon \& Baum, 1971; Hunsicker, Nelson, \& Reid, 1973; Prado-Alcala, Bush, Steele, \& Reid, 1973).

In nearly all laboratory studies testing various ways to reduce persisting avoidance, Ss are tested after only minimal training (in this paradigm, usually after 25 or so training trials). Baum (1968) gave rats either 50 or 100 additional trials after the avoidance was acquired. This overtraining increased persistence of responding only if the rat failed to avoid and therefore received a footshock during the additional training. This study was designed to test the efficiency of treatments known to reduce avoidance responding after minimal training with rats in which the avoidance was well established (after over 1,000 training trials).

\section{METHOD}

\section{Subjects and Apparatus}

Fifteen adult male Sprague-Dawley rats were each fixed with chronically indwelling bipolar electrodes or received sham surgeries. Electrode tips were aimed for the lateral hypothalamus-medial forebrain bundle. Subsequent histological inspection verified that sites of ICS, the activation of which were

*This study was supported by Bradley University's Board for Research which administers NSF Grant GU 3320. We thank Cindy Royer, Angela Spears, and Frederic Sautter for assistance with the daily testing of Ss. This study is part of a research program that H. R. Miller, Southern Illinois University, codirected. used as part of the procedure, were in the lateral hypothalamus and probably activated, almost exclusively, the medial forebrain bundle.

All ICS was $60-\mathrm{Hz}$ sine waves of $.25-\mathrm{sec}$ duration with intensity individually determined for each rat but always between 40 and 65 microA. Footshock was $1.3 \mathrm{~mA}$ and was generated by a Grason-Stadler shock source and scramble. To avoid interaction between sources of ICS and footshock, the leads to the sources of stimulation were never connected simultaneously.

The avoidance apparatus was similar to one described by Baum (1965). Briefly, it was a Plexiglas box with an electrifiable grid floor and a retractable ledge extending $7 \mathrm{~cm}$ through the width $(30.5 \mathrm{~cm})$ of one side of the square box, $15.2 \mathrm{~cm}$ above the floor. Weight of the rat closed a switch in the ledge.

\section{Procedure}

After tests for the reinforcing value of ICS, rats were given avoidance training. The training procedure and general features of treatment and testing were the same as those used by Gordon and Baum (1971) and Hunsicker et al (1973). Without habituation to the chamber, rats were placed directly on the grid. At the end of $10 \mathrm{sec}$, shock began and continued until the rat climbed onto the ledge. Thirty seconds later the ledge retracted, returning the rat to the grid and beginning a new trial. Shock was avoided if the rat climbed to the ledge before $10 \mathrm{sec}$ elapsed. If the rat left the ledge before $30 \mathrm{sec}$, the ledge retracted, returned, and a new trial was begun. Rats received 100 trials a day for 10 consecutive days, or 1,000 training trials. On the 990th trial, the shelf was retracted, and $10 \mathrm{sec}$ of unavoidable shock was delivered to ensure that all rats had received severe shock just prior to treatment.

Rats were randomly assigned to three experimental conditions, five rats to a group, with the restriction that five animals which pressed the most for ICS were placed in one group just prior to treatments. On the day of treatment, rats cortinued training until they made 10 consecutive avoidance ${ }^{*}$ ponses, which was always accomplished by the 11 th trial. The ats were removed from the chamber, footshock leads were d. nnected, and the lectrode leads for those rats to receive ICS .onnected. Rats were then given one of three treatments: (a) for one group, the ledge was removed from the chamber and $S$ placed into the chamber for $5 \mathrm{~min}$, a response prevention treatment (RP): (b) for another group, the ledge was also removed thereby preventing responding for the $5 \mathrm{~min}$ the rat was in the chamber, but ICS of $0.25 \mathrm{sec}$ every $2.0 \mathrm{sec}$ was also given, a counterconditioning treatment (RP + ICS); (c) for the third 
Table 1

Treatments and Trials to Criteria

\begin{tabular}{|c|c|c|c|c|c|c|}
\hline & \multicolumn{6}{|c|}{ Treatments } \\
\hline & \multicolumn{2}{|c|}{ None } & \multicolumn{2}{|c|}{ Response Prevention (RP) } & \multicolumn{2}{|c|}{ RP With ICS } \\
\hline . & $5 \mathrm{Min}$ & $30 \mathrm{Min}$ & 5 Min & $30 \mathrm{Min}$ & 5 Min & $30 \mathrm{Min}$ \\
\hline $\begin{array}{l}\text { Raw } \\
\text { Data }\end{array}$ & $\begin{array}{r}825 \\
900 \\
1208 \\
1361 \\
1502\end{array}$ & $\begin{array}{r}361 \\
501 \\
992 \\
1124 \\
1325\end{array}$ & $\begin{array}{r}572 \\
763 \\
1096 \\
1171 \\
1741\end{array}$ & $\begin{array}{r}133 \\
162 \\
792 \\
795 \\
1171\end{array}$ & $\begin{array}{l}265 \\
287 \\
502 \\
640 \\
964\end{array}$ & $\begin{array}{l}0 \\
0 \\
0 \\
0 \\
2\end{array}$ \\
\hline $\begin{array}{l}\text { Mean } \\
\text { Range }\end{array}$ & $\begin{array}{c}1159.2 \\
677 \\
\end{array}$ & $\begin{array}{l}860.6 \\
964 \\
\end{array}$ & $\begin{array}{l}1068.6 \\
1169\end{array}$ & $\begin{array}{c}610.6 \\
1038\end{array}$ & $\begin{array}{l}531.6 \\
699 \\
\end{array}$ & $\begin{array}{l}0.4 \\
2 \\
\end{array}$ \\
\hline
\end{tabular}

group, the rats spent the $5 \mathrm{~min}$ in a pail next to the chamber. All Ss were handled the same number of times and as similarly as possible.

At the end of the 5-min treatment times, rats were placed on the returned ledge. Trials then continued as in training, except no footshock was delivered; however, the sounds of the scrambler continued as before. Ss were kept in the chamber until they had spent 5 min on the grid.

Seven days after rats met criterion for extinction, they were returned to the chamber for $75 \mathrm{~min}$, with the shock source disconnected to test for recovery of responding. The following day, they were given another 100 training trials with the possibility of shock. On the 90 th trial, $10 \mathrm{sec}$ of unavoidable shock was delivered. The next day, Ss received treatment as before with the exception that the time of treatment was increased from 5 to $30 \mathrm{~min}$. Criterion for extinction remained the same.

The measures taken prior to treatment were time on the grid (including shock and no shock time), number of avoidances, and instances when a $S$ avoided on the first trial of a day's session. Measures taken after a treatment were trials, "avoidances" (climbs to ledge before $10 \mathrm{sec}$ of the trial elapsed), and time on the grid prior to meeting the criterion of 5 consecutive minutes on the grid.

\section{RESULTS}

Beginning with about the fifth training trial, rats were typically avoiding on all trials of a session. Across the 1,000 trials, no rat avoided on less than $94 \%$ of the trials, with the most frequent nonavoidance trials being at the first of training and on the first trial of a day thereafter. Rats took a mean of $146 \mathrm{sec}$ of shock across all trials with $61 \mathrm{sec}$ of shock during the first 100 trials leaving a balance of only $85 \mathrm{sec}$ to be distributed across the other 900 trials.

Simple analyses of variance (ANOVA) on the pretreatment measures of time on grid and number of avoidances with data grouped according to $\mathrm{Ss}^{\prime}$ treatments suggested that there were no reliable differences among groups prior to treatment ( $\mathrm{F}$ for grid time $=.47 ; \mathrm{F}$ for avoidance $=1.3, \mathrm{df}=2 / 12, \mathrm{p}>.25$ ). These analyses suggest that analyses of posttreatment scores would not be biased by pretreatment variables. Kendall's coefficient of concordance of the three measures of perseveration of responding after $5 \mathrm{~min}$ of treatment was .84 . Since pretreatment measures are of little consequence to conclusions to be drawn and since trials to criterion correlated highly with other posttreatment measures, the analyses were confined to simple ANOVA of trials to extinction.

Data of the two extinction tests appear in Table 1. ANOVA of the first extinction following $5 \mathrm{~min}$ of treatment suggested reliable differences among groups $(\mathrm{F}$ $=4.2, \mathrm{df}=2 / 12, \mathrm{p}<.05)$. Using the method of Dunnett (Winer, 1962), results with the two treatment analogues were compared to the results of no treatment. The analyses suggested that the performance of Ss getting only response prevention did not differ reliably from the performance of no treatment controls $(t=.4)$, however, the performance of the rats getting response prevention plus periodic ICS did differ from that of the no treatment controls $(\mathrm{t}=2.8, \mathrm{p}<.025)$. There was a considerable range of responding during the second 75-min test session without footshock (0 to 144 responses). ANOVA of these data indicated no reliable differences among groups $(\mathrm{F}=.32)$.

ANOVA of the data of extinction after $30 \mathrm{~min}$ of treatment yielded an $F=7.7$, df $=2 / 12, p<.01$. Dunnett's test indicated no difference in performance between rats of no treatment and rats of response prevention $(t=1.1)$, however, rats receiving response prevention plus ICS did differ from rats of no treatment $(t=3.8, p<.005)$. After the second extinction, all rats were returned to the chamber on subsequent days for $10 \mathrm{~min}$ a day. Some of each group avoided without fail during these tests. A few were tested nearly daily for a couple of months with an occasional day of no tests. At the end of these days of training, some rats continued to avoid without fail. The data of these follow ups were not systematic enough to provide comparisons among groups, however, at least one rat on each group continued responding for weeks after its last "extinction."

\section{DISCUSSION}

Baum (1968) found minimal prolongation of persisting avoidance after extending training beyond 10 consecutive avoidances by 50 or 100 "overtraining" trials. The enhancement of persisting avoidance was negligible unless the rat received a shock sometime during the extended training. The effect of 
prolonged training in this experiment (about 1,000 trials) was to entrench the avoidance responding. The no treatment control rats frequently did not "extinguish" responding, but met criterion by apparently being so fatigued that they could no longer climb to the shelf. Considering that 100 responses takes about an hour to complete and considering that these rats took a mean of 1,100 trials to extinguish, it is no wonder that after $11 \mathrm{~h}$ of responding they stopped.

A claim made for implosion therapy (flooding or response prevention) is that it is the technique of choice for more established, engrained, and more "dynamically" related phobias. Our data do not support the idea that implosion is the technique of choice for reducing well-established "avoidance." On the contrary, out data indicate that a counterconditioning procedure is the superior technique for reduction of entrenched as well as recently established avoidance.

\section{REFERENCES}

Baum, M. An automated apparatus for the avoidance training of rats. Psychological Reports, 1965, 16, 1205-1211.

Baum, M. Efficacy of response prevention (flooding) in facilitating the extinction of an avoidance response in rats: The effect of overtraining the response. Behavior Research \& Therapy, 1968, 6, 197-203.
Baum, M. Extinction of avoidance responding through response prevention (flooding). Psychological Bulletin, 1970, 74, 276-284.

Buss, R. S , \& Reid, L. D. Deconditioning persisting avoidance: Spacing counterconditioning periods during response prevention. Bulletin of the Psychonomic Society, 1973, 2, 418-420.

Gordon, A., \& Baum, M. Increased efficacy of flooding (response prevention) in rats through positive intracranial stimulation. Journal of Comparative \& Physiological Psychology, 1971, 75, 68-72.

Hunsicker, J. P., Nelson, T. C., \& Reid, L. D. Two kinds of intracranial stimulation as counterconditioners of persisting avoidance in rats. Physiological Psychology, 1973, 1, 227-230.

Prado-Alcala, R., Bush, H., Steele, D., \& Reid, L. Brief flooding and counterconditioning as treatments for persisting avoidance. Phy siological Psychology, 1973, 4, 389-393.

Reid, L. D. Processes of fear reduction in systematic desentization: An addendum to Wilson and Davison (1971). Psych ological Bulletin, 1973, 79, 107-109.

Wilson, E. H., \& Davison, G. C. Processes of fear reduction in systematic desensitization: Animal studies. Psychological Bulletin, 1971, 76, 1-14.

Winer, B. Statistical principles in experimental design. New York: McGraw-Hill, 1962.

(Received for publication February 11, 1974.)

\title{
Repetition effects and retroactive facilitation: Immediate and delayed recall performance*
}

\author{
DONALD ROBBINS $\dagger$ and JAMES F. BRAY \\ Emory University, Atlanta, Georgia 30322
}

\begin{abstract}
A study was conducted using a continuous paired-associate task varying the retention interval after one of two presentations of a pair of words. The lag between presentations was also varied. Half of the two presentation items represented an A-B, A-C negative transfer design while the other half were A-B, A-B items. Two different groups were instructed, with regard tc the A-B, A-C items, to recall on test trials only Response B or only Response C. Under some A-B, A-C conditions, retroactive facilitation was found. Specifically, with a relatively long retention interval and short lags, the presentation of A-C was as effective as a second presentation of $A-B$ for the recall of $B$.
\end{abstract}

It has been shown that increasing the spacing or lag between repetitions of a word pair leads to better recall performance on a paired-associate task (see Bjork, 1970;

*This research was supported by Grant MH 20331 from the National Institute of Mental Health.

tReprint requests should be sent to: Donald Robbins, Department of Psychology, Emory University, Atlanta, Georgia 30322 .
Melton, 1970). However, both Peterson, Wampler, Kirkpatrick, and Saltzman (1963) and Young (1971) reported a limit to this "spacing" effect, namely, at very long lags performance declined. Hence, the function relating proportion recalled and the lag between repetitions (for relatively long retention intervals) is concave downward. Furthermore, Peterson, Hillner and Saltzman (1962) found the spacing effect only when the 